\title{
A Missense Variation in Human Casein Kinase I Epsilon Gene that Induces Functional Alteration and Shows an Inverse Association with Circadian Rhythm Sleep Disorders
}

\author{
Atsuko Takano', Makoto Uchiyama ${ }^{2}$, Naofumi Kajimura ${ }^{3}$, Kazuo Mishima $^{4}$, Yuichi Inoue ${ }^{5}$, Yuichi Kamei ${ }^{6}$, \\ Tsuyoshi Kitajima ${ }^{7}$, Kayo Shibui ${ }^{2}$, Masaaki Katoh ${ }^{3}$, Tsuyoshi Watanabe ${ }^{3}$, Yuki Hashimotodani', \\ Toru Nakajima $^{8}$, Yuji Ozeki', Toru Hori ${ }^{3}$, Naoto Yamada', Ryoichi Toyoshima' ${ }^{10}$, Norio Ozaki ${ }^{7}$, \\ Masako Okawa', Katsuya Nagai', Kiyohisa Takahashi ${ }^{2,3,6}$, Yasushi Isojima', Toshio Yamauchi ${ }^{10}$ and \\ Takashi Ebisawa*, 10,11 \\ 'Division of Protein Metabolism, Institute for Protein Research, Osaka University, Osaka, Japan; ${ }^{2}$ Department of Psychophysiology, National \\ Center of Neurology and Psychiatry (NCNP), Chiba, Japan; ${ }^{3}$ Musashi Hospital, NCNP, Tokyo, Japan; ${ }^{4}$ Department of Psychiatry, Akita University \\ School of Medicine, Akita, Japan; ${ }^{5}$ Department of Psychiatry, Juntendo University, School of Medicine, Tokyo, Japan; ${ }^{6}$ Kohnodai Hospital, NCNP, \\ Chiba, Japan; ${ }^{7}$ Department of Psychiatry, Fujita Health University School of Medicine, Aichi, Japan; ${ }^{8}$ Department of Neuropsychiatry, Kyorin \\ University, School of Medicine, Tokyo, Japan; ${ }^{9}$ Department of Psychiatry, Shiga University of Medical Science, Shiga, Japan; ${ }^{10}$ Department of \\ Neuropsychiatry, Saitama Medical School, Saitama, Japan; "'Project Research Division in Research Center for Genomic Medicine, Saitama \\ Medical School, Saitama, Japan
}

\begin{abstract}
Recent studies have shown that functional variations in clock genes, which generate circadian rhythms through interactive positive/ negative feedback loops, contribute to the development of circadian rhythm sleep disorders in humans. Another potential candidate for rhythm disorder susceptibility is casein kinase I epsilon $(\mathrm{CK} \mid \varepsilon)$, which phosphorylates clock proteins and plays a pivotal role in the circadian clock. To determine whether variations in CKle induce vulnerability to human circadian rhythm sleep disorders, such as delayed sleep phase syndrome (DSPS) and non-24-h sleep-wake syndrome (N-24), we analyzed all of the coding exons of the human CKl\& gene. One of the variants identified encoded an amino-acid substitution $\mathrm{S} 408 \mathrm{~N}$, eliminating one of the putative autophosphorylation sites in the carboxyl-terminal extension of CKle. The N408 allele was less common in both DSPS $(p=0.028)$ and $\mathrm{N}-24$ patients ( $p=0.035)$ compared to controls. When DSPS and $\mathrm{N}-24$ subjects were combined, based on an a priori prediction of a common mechanism underlying both DSPS and N-24, the inverse association between the N408 allele and rhythm disorders was highly significant $(p=0.0067$, odds ratio $=0.42,95 \%$ confidence interval: $0.22-0.79)$. In vitro kinase assay revealed that CKl $\varepsilon$ with the $S 408 \mathrm{~N}$ variation was

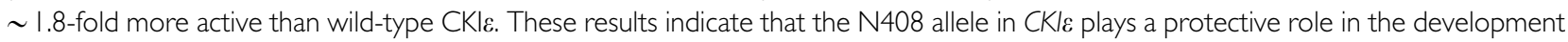
of DSPS and N-24 through alteration of the enzyme activity.

Neuropsychopharmacology (2004) 29, 190 I-1909, advance online publication, 9 June 2004; doi:I 0. I 038/sj.npp. 1300503
\end{abstract}

Keywords: casein kinase; polymorphism, single nucleotide; phosphorylation; biological clocks; case-control studies; risk factors

\section{INTRODUCTION}

In mammals, including humans, circadian cycles of approximately $24 \mathrm{~h}$ are observed in behavior and physiology, including cycles of sleep, hormone secretion, and core body temperature. The master circadian pacemaker is localized in the hypothalamic suprachiasmatic nucleus

\footnotetext{
*Correspondence: Dr T Ebisawa, Department of Neuropsychiatry, Saitama Medical School, 38 Morohongo, Moroyama-cho, Iruma-gun, Saitama 350-0495, Japan, Tel: + 8149276 1213, Fax: + 8I 49276 1622, E-mail: tebisawa@saitama-med.ac.jp

Received 12 August 2003; revised 9 April 2004; accepted 12 May 2004 Online publication: 15 May 2004 at http://www.acnp.org/citations/ Npp05 I 50403365/default.pdf
}

(SCN). Clock genes, Per1/2/3, Cry1/2, Bmal1, and CLOCK are expressed in the SCN and produce a nearly $24 \mathrm{~h}$ cycle through interacting positive/negative feedback loops (Harmer et al, 2001; Reppert and Weaver, 2002). BMAL1 and CLOCK proteins bind to E-box elements and activate transcription of Per and Cry genes. As the PERs and CRYs are translated, they enter the nucleus and inhibit BMAL1/ CLOCK-driven transcription in the negative feedback loop. The circadian pacemaker is synchronized (entrained) to the $24 \mathrm{~h}$ day, primarily by the environmental light/dark cycle.

Certain human sleep disorders, designated circadian rhythm sleep disorders, are attributed to the disruption of the circadian timing system (Weitzman et al, 1981; Campbell et al, 1999; Wijnen et al, 2002). Patients with circadian 
rhythm sleep disorders, such as delayed sleep phase syndrome (DSPS), advanced sleep phase syndrome (ASPS), and non-24-h sleep-wake syndrome (N-24), fail to adjust their sleep/wake cycle to the daily schedule required for social life. Despite normal sleep architecture, sleep onset and offset are persistently delayed (DSPS) or advanced (ASPS) compared to the societal norm. N-24 patients suffer from daily delays of sleep onset and offset times, with the consequence of progressive cycling through the $24 \mathrm{~h}$ environmental day. The pathogenesis of DSPS and N-24 is not yet known, but several possible mechanisms have been proposed: reduced sensitivity of the oscillator to photic entrainment, a prolonged intrinsic period beyond the range of entrainment to $24 \mathrm{~h}$ day, and abnormal coupling of the sleep/wake cycle to the circadian rhythm (Weitzman et al, 1981; Campbell et al, 1999; Uchiyama et al, 2000). It is estimated that $0.13 \%$ (in Japan) (Yazaki et al, 1999), $0.17 \%$ (in Norway) (Schrader et al, 1993), and $0.7 \%$ (in USA) (Ando et $a l, 1995$ ) of the general population suffer from DSPS, while the prevalence of N-24 is lower. Genetic factors reportedly confer predisposition to ASPS and DSPS (AncoliIsrael et al, 2001; Jones et al, 1999; Reid et al, 2001).

Analysis of animals and humans with altered circadian rhythms demonstrated that casein kinase I epsilon (CKI $\varepsilon$ ) (and presumably its most closely related homolog, CKI $\delta$ ) plays a crucial role in regulating the circadian pacemaker (Eide and Virshup, 2001). CKI $\varepsilon$ (and CKI $\delta$ ) phosphorylates PER proteins, leading to their destabilization and relocalization (Takano et al, 2000; Vielhaber et al, 2000; Keesler et al, 2000; Akashi et al, 2002; Camacho et al, 2001). CKI $\varepsilon / \delta$ have long carboxyl-terminal (C-terminal) extensions, which can be autophosphorylated, with the consequence of autoinhibition of kinase activity (Graves and Roach, 1995; Cegielska et al, 1998). Double-time ( $d b t)$ gene, a Drosophila homolog of mammalian $C K I \varepsilon$, was shown to alter or ablate circadian rhythm when functionally mutated (Price et al, 1998). In hamsters, a point mutation in CKIE that decreases kinase activity causes the semidominant short-period tau phenotype (Ralph and Menaker, 1988; Lowrey et al, 2000). A recent report showed that, in humans, familial ASPS can be induced by a Per2 S662G mutation, which reduces $\mathrm{CKI} \varepsilon$-induced phosphorylation of the PER2 protein (Toh et al, 2001). We have reported that a Per3 gene haplotype, in which one of the variations lies close to the $\mathrm{CKI} \varepsilon$ target site and presumably alters PER3 protein phosphorylation, is significantly associated with DSPS (Ebisawa et al, 2001). These results suggest the possibility that human CKIE (hCKIE) gene may also be involved in susceptibility to circadian rhythm sleep disorders.

Accordingly, we set out to screen the complete coding region of the CKIE gene, as well as adjacent exon-intron boundaries for the presence of genetic variants in circadian rhythm sleep disorder patients and controls.

\section{MATERIALS AND METHODS}

\section{Subjects}

In all, 98 DSPS patients (60 males; 38 females; mean age: $27.1 \pm 9.1$ years) and $39 \mathrm{~N}-24$ patients (29 males; 10 females; mean age: $26.9 \pm 8.4$ years) were recruited. Diagnosis was assigned by a trained psychiatrist according to the
International Classification of Sleep Disorders (ICSD1990) criteria. All of the patients were unrelated, except for two sibling pairs, of which each consisted of a patient with DSPS and a patient with $\mathrm{N}-24$. In a combined analysis of DSPS and $\mathrm{N}-24$, two of the DSPS subjects with siblings of $\mathrm{N}-24$ were excluded from the DSPS/N-24 group to avoid an increase in the Type I error rate. Neither of the sibling pairs carried the $5408 \mathrm{~N}$ variation. Another three patients with DSPS had relatives with probable DSPS, who were not involved in this study, and another patient with N-24 had a first-degree relative with severe insomnia. In all, 138 healthy subjects were recruited as controls (81 males; 57 females; mean age: $32.1 \pm 8.6$ years). Control individuals were free from sleep disorders or psychoses. All of the study subjects were sighted. In total, 59 DSPS patients, $36 \mathrm{~N}-24$ patients, and 107 control subjects of the study population were reported previously (Iwase et al, 2002), while the others were newly recruited for this study. In order to minimize the effect of the population stratification, which may cause false results, all of the study subjects were Japanese and recruited in mainland Japan. The controls were geographically matched to the patients. Written informed consent was obtained from the subjects. The protocol was approved by the ethics committee of Saitama Medical School and the participating institutes.

Blood samples were drawn by venipuncture and genomic DNAs were prepared from leukocytes using QIAamp DNA Blood Maxi Kit or QIAGEN Blood \& Cell Culture DNA Midi Kit (QIAGEN, Hilden, Germany).

\section{DNA Analysis}

Polymerase chain reaction/single-strand conformation polymorphism (PCR-SSCP) analysis was used to screen for variations in all coding exons of the CKIE gene. Fluorescein-labelled primers to amplify each of the coding exons and adjacent exon-intron junctions were derived from the genomic structure determined by alignment of the cDNA and genomic sequence of hCKI 8 (AB024597 and AL020993, respectively) (Table 1). PCR was performed in a total volume of $50 \mu \mathrm{l}$ containing $100 \mathrm{ng}$ DNA, $0.5 \mu \mathrm{M}$ of each primer, $1 \times$ PCR buffer II, $0.2 \mathrm{mM}$ dNTPs, $1.5 \mathrm{mM} \mathrm{Mg}^{2+}$, and $1.25 \mathrm{U}$ of AmpliTaq Gold DNA Polymerase. Conditions for PCR were preincubation at $95^{\circ} \mathrm{C}$ for $9 \mathrm{~min}$ to denature the DNA and to activate the polymerase, followed by 45 cycles at $95^{\circ} \mathrm{C}$ for $20 \mathrm{~s}, 63-68^{\circ} \mathrm{C}$ for $45 \mathrm{~s}$, and $72^{\circ} \mathrm{C}$ for $1 \mathrm{~min}$, with a subsequent final extension step at $72^{\circ} \mathrm{C}$ for $10 \mathrm{~min}$.

SSCP electrophoresis was carried out on a denaturing gel in a DSQ-500S DNA sequencer (Shimadzu, Kyoto, Japan) basically as described (Ebisawa et al, 2001). Briefly, $1 \mu \mathrm{l}$ of PCR products were mixed with $19 \mu$ l of formamide buffer (90\% formamide, $5 \mathrm{mM}$ EDTA, $10 \mathrm{mg} / \mathrm{ml}$ Blue dextran), heated at $80^{\circ} \mathrm{C}$ for $7 \mathrm{~min}$, and $1.5 \mu \mathrm{l}$ of the sample mixture was electrophoresed on a 0 or $5 \%$ glycerol SSCP Gel at $20^{\circ} \mathrm{C}$, according to the manufacturer's protocol. Genomic DNAs in which variants were detected by SSCP were amplified using primers that encompass the SSCP-amplified region, and purified using QIAquick PCR Purification Kit (QIAGEN). Sequence reactions were performed on both strands using internal primers and the BigDye Terminator Cycle Sequencing Ready Reaction Kit (Applied Biosystems, Foster City, CA, USA) according to the protocol of the 
Table I Primers Used for SSCP Analysis of the Human CKIE Gene

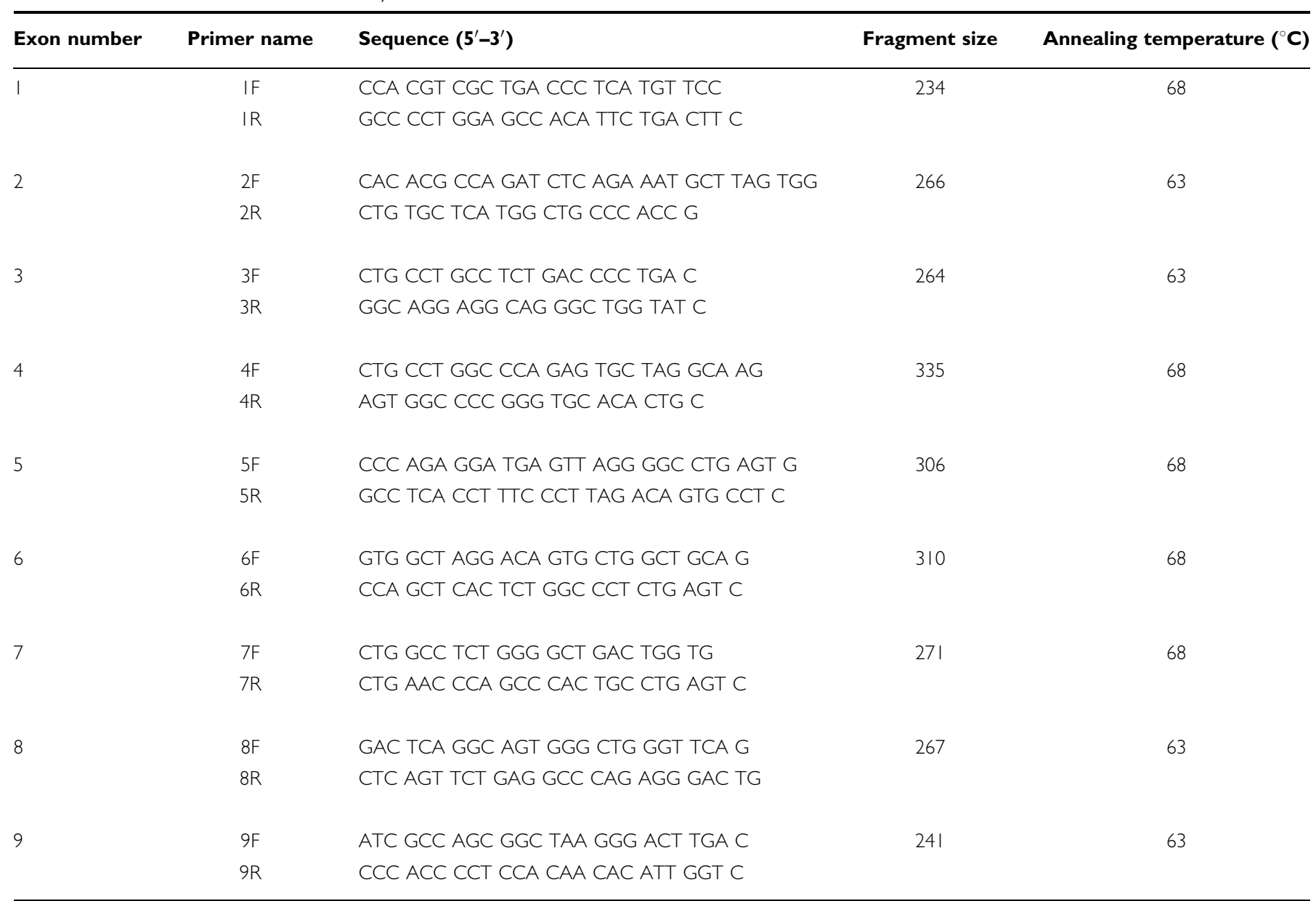

$\mathrm{F}$ or $\mathrm{R}$, in the primer names indicate the forward or reverse orientation of each primer.

manufacturer, and detected by an ABI PRISM 310 Genetic Analyzer (Applied Biosystems). One of the PCR-amplified fragments in which a deletion was detected by direct sequence analysis was cloned into pGEM-T Easy vector (Promega, Madison, WI, USA), and multiple isolates were sequenced on both strands. To determine the frequency of the S408N variant, all of the samples were amplified by PCR using 9F and 9R primers in Table 1 and subjected to either SSCP and/or denaturing high-performance liquid chromatography (DHPLC) analysis, followed by sequencing reactions as described above.

For DHPLC analysis, PCR products were denatured at $98^{\circ} \mathrm{C}$ for $30 \mathrm{~s}$ and $95^{\circ} \mathrm{C}$ for $7 \mathrm{~min}$, followed by gradual reannealing from 95 to $15^{\circ} \mathrm{C}$ over $40 \mathrm{~min}$. The crude PCR products $(5-7 \mu \mathrm{l})$ were then injected into a DNASep column and separated through a $13.5-15.75 \%$ acetonitrile gradient at $61^{\circ} \mathrm{C}$ using a WAVE DNA Fragment Analysis System (Transgenomic, Omaha, NE, USA).

\section{Purification of Recombinant Proteins}

The partial cDNAs encoding mouse PER1 (mPER1) (amino acids 547-799), rat PER2 (rPER2) (486-793), and mouse PER3 (mPER3) (367-880) fragments, which correspond to the $\mathrm{CKI} \varepsilon$-binding regions (Takano, A et al, unpublished observation), were subcloned into pGEX4T-3 or pGEX6P-1 vector (Pharmacia, Peapack, NJ, USA) for the production of glutathione- $S$-transferase (GST)-fused recombinant proteins. The partial fragments of PERs were used for in vitro kinase assay, because it is practically impossible to obtain enough amount of intact full-length PER proteins due to their instability when expressed in Escherichia coli. The PER fragments we used correspond to the CKI $\varepsilon$-binding domains which contain the phosphorylation sites; therefore, they can be properly used for in vitro kinase assay of CKIEs to compare the kinase activity against PERs.

The $\mathrm{S} 408 \mathrm{~N}$ substitution was introduced into the rat $\mathrm{CKI} \varepsilon$ ( $\mathrm{rCKI} \varepsilon$ ) cDNA by site-directed mutagenesis using PCR, generating $\mathrm{CKI} \varepsilon-\mathrm{S} 408 \mathrm{~N}$. The amino-acid sequence of $\mathrm{rCKI} \varepsilon$ is identical to that of $\mathrm{hCKI} \varepsilon$, except for two amino acids. Neither of the two amino acids is a phosphoacceptor residue. The expression constructs encoding GST-fused wild-type $\mathrm{rCKI} \varepsilon$ (GST-CKI $\varepsilon$-WT) and $\mathrm{CKI} \varepsilon$-S408N (GST$\mathrm{CKI} \varepsilon-\mathrm{S} 408 \mathrm{~N}$ ) were prepared using pGEX4T-3 (for $\alpha$-casein) or pGEX6P-1 (for GST-PERs) vector. Escherichia coli (E. coli) strain BL21 (DE3) was transformed with the expression plasmids and the fusion proteins expressed were purified with glutathione sepharose $4 \mathrm{~B}$ (Pharmacia) according to the manufacturer's protocol. GST-CKI $\varepsilon$ proteins were easily degraded, therefore, for the use in kinetic analysis 
against $\alpha$-casein, the fusion proteins were further purified by immunoprecipitation with the specific antibody against the $\mathrm{C}$-terminal end of $\mathrm{rCKI} \varepsilon$ to remove the contamination of partially degraded recombinant $\mathrm{rCKI} \varepsilon$ (Takano et al, 2000). To perform in vitro kinase assay using GST-fused PER fragments as substrates, GST tag was removed from GST-CKI $\varepsilon$ using PreScission protease (Amersham) to discriminate phosphorylated GST-PERs and autophosphorylated $\mathrm{rCKI} \varepsilon$ on electrophoretic mobility.

\section{In Vitro Kinase Assay and Kinetic Analysis}

Kinase reactions were performed in buffer containing $45 \mathrm{mM}$ Tris-HCl, $\mathrm{pH} 7.4,9 \mathrm{mM} \mathrm{MgCl}_{2}, 0.9 \mathrm{mM} \beta$-mercaptoethanol, $40 \mu \mathrm{M}$ ATP, $74 \mathrm{kBq}$ of $\left[\gamma^{32} \mathrm{P}\right]$, kinase and $\alpha$-casein or GST-PER in a final volume of $20 \mu$ l. Approximately $40 \mathrm{ng}$ of the immunoprecipitated GST-CKI $\varepsilon$ (for $\alpha$ casein), 2 pmol of rCKI $\varepsilon$ (for GST-mPER1 and GST-rPER2), or 10 pmol of rCKIE (for GST-mPER3) was added to the reaction mixture. Varying concentrations of $\alpha$-casein $(0-100 \mu \mathrm{M})$, or $20 \mathrm{pmol}$ of GST-mPER1, GST-rPER2, or GST-mPER3 protein, was used as a substrate. The amount of $\mathrm{rCKI} \varepsilon$, GST-CKI $\varepsilon$, or GST-PER used in each reaction was confirmed by SDS-polyacrylamide gel electrophoresis (SDS-PAGE), followed by Coomassie brilliant blue staining using bovine serum albumin as a standard, revealing that the difference in the amount of $\mathrm{rCKI} \varepsilon$ or GST-CKI $\varepsilon$ in each experiment was smaller than $7.3 \%$ of the wild type. The kinase reactions for $\alpha$-casein were allowed to proceed at $37^{\circ} \mathrm{C}$ for $10 \mathrm{~min}$, because the enzyme activity was linear with time for up to $20 \mathrm{~min}$ (data not shown). Reactions were terminated by addition of $20 \mu \mathrm{l}$ SDS-PAGE sample buffer. A part of the reaction mixture was subjected to electrophoresis on $12 \%$ (for $\alpha$-casein) or $7.5 \%$ (for GST-PERs) polyacrylamide gels, and $\left[{ }^{32} \mathrm{P}\right]$ incorporation into the substrates was determined by a BAS-2000 image analyzer. When $\alpha$-casein was used as a substrate, the data were presented as a double-reciprocal plot and $V_{\max }$ and $K_{\mathrm{m}}$ were obtained using computer software (Kaleida Graph, Abelbeck Software).

\section{Statistical Analysis}

Departure from Hardy-Weinberg equilibrium was tested using a $\chi^{2}$ goodness-of-fit test. The allele and genotype frequencies were compared by means of Fisher's exact test. All $p$-values reported are two-tailed. Correction for multiple testing for the analyses in the previous studies was not performed since a considerable number of subjects were newly recruited for this study, which was conducted with a pre-established hypothesis (Perneger, 1998). Unpaired $t$-test was performed to compare the amounts of incorporated $\left[{ }^{32} \mathrm{P}\right]$ into GST-PER by CKI $\varepsilon-\mathrm{WT}$ and $\mathrm{CKI} \varepsilon-\mathrm{S} 408 \mathrm{~N}$.

\section{RESULTS}

Using PCR-SSCP and subsequent sequencing of the PCRamplified fragments, all of the coding exons and flanking exon-intron boundaries of the CKIE gene were screened for sequence variations. In an initial screen of 35 genomic DNA samples (17 of DSPS and 18 of $\mathrm{N}-24$ ), three sequence variants were identified (Table 2). One single-nucleotide
Table 2 Sequence Variations Identified in the Human CKI\& Gene

\begin{tabular}{llc}
\hline $\begin{array}{l}\text { DNA } \\
\text { polymorphism }\end{array}$ & Location & $\begin{array}{l}\text { Amino-acid } \\
\text { substitution }\end{array}$ \\
\hline $5 I C>T$ & Exon I & None \\
$77-63$ 77-60delGGCG & Intron I & None \\
$1223 G>A$ & Exon 9 & S408N \\
$1263 \mathrm{~A}>\mathrm{G}$ & Exon 9 (3'-untranslated region) & None \\
\hline
\end{tabular}

Variations were named basically according to den Dunnen and Antonarakis (200 I). Nucleotide numbers refer to the human CKle cDNA sequence (AB024597) with the A of the ATG start codon denoted as I. The S408N variation was submitted to DDBJ (http://www.ddbj.nig.ac.jp/, Accession no. AB080742)

Table 3 Frequency of the S408N Variant in Patients and Controls

\begin{tabular}{lcccc}
\hline & \multicolumn{4}{c}{ Allele frequency } \\
\cline { 2 - 5 } & $\boldsymbol{n}$ & $\mathbf{N 4 0 8}(\%)$ & $\mathbf{S 4 0 8}(\%)$ & p-value \\
\hline Control & 276 & $34(12.3)$ & $242(87.7)$ \\
DSPS & 196 & $12(6.1)$ & $184(93.9)$ & $0.028^{\mathrm{a}}$ \\
N-24 & 78 & $3(3.8)$ & $75(96.2)$ & $0.035^{\mathrm{b}}$ \\
DSPS/N-24 & 270 & $15(5.6)$ & $255(94.4)$ & $0.0067^{\mathrm{c}}$ \\
\hline
\end{tabular}

${ }^{a}$ Odds ratio $(O R)=0.46,95 \%$ confidence interval $(\mathrm{Cl}): 0.23-0.92$.

${ }^{\mathrm{b}} \mathrm{OR}=0.28,95 \% \mathrm{Cl}: 0.085-0.95$.

${ }^{\mathrm{c}} \mathrm{OR}=0.42,95 \% \mathrm{Cl}: 0.22-0.79$.

variation $(51 \mathrm{C}>\mathrm{T})$ was located in exon 1 , another variation $(1223 \mathrm{G}>\mathrm{A})$ in exon 9 , and one intronic deletion of $4 \mathrm{bp}$ (77-63_77-60delGGCG) resided upstream of exon 2. The $1223 \mathrm{G}>\mathrm{A}$ exonic variation predicted an amino-acid substitution, S408N. S408 is located in the C-terminal extension of the CKI $\varepsilon$ and is conserved in CKI $\varepsilon$ s of humans, hamsters, mice, rats, and Xenopus laevis, as well as in CKI $\delta$ s of humans and rats. Previous studies demonstrated that the Cterminal extensions of mammalian $\mathrm{CKI} \varepsilon$ (and $\mathrm{CKI} \delta$ ) can be autophosphorylated, inhibiting the kinase activity (Graves and Roach, 1995; Cegielska et al, 1998), and that S408 is one of the putative phosphoacceptor residues (Gietzen and Virshup, 1999). Therefore, the S408N variation is likely to eliminate one of the autophosphorylation sites, resulting in decreased autophosphorylation and increased enzyme activity. The $51 \mathrm{C}>\mathrm{T}$ exonic variation resulted in synonymous substitution. Neither the $51 \mathrm{C}>\mathrm{T}$ variation nor the intronic deletion (77-63_77-60delGGCG) appeared to affect known splice sites or to create better splice donor/acceptor consensus sequences, based on visual examination of the sequence context, so functional alterations appeared unlikely (Burset et al, 2000). Therefore, we focused on the $\mathrm{S} 408 \mathrm{~N}$ variation for further analysis.

The frequency of the $5408 \mathrm{~N}$ variation was analyzed in a total of 137 circadian rhythm sleep disorder patients and 138 control subjects. Allele and genotype distributions are shown in Tables 3 and 4. No significant deviation from Hardy-Weinberg equilibrium was detected for the variation either in patients or in controls. The distribution analysis resulted in the detection of an additional silent sequence variation $(1263 \mathrm{~A}>\mathrm{G})$ in the $3^{\prime}$-untranslated region of the 
Table 4 Genotype Distribution of the S408N Variant in Patients and Controls

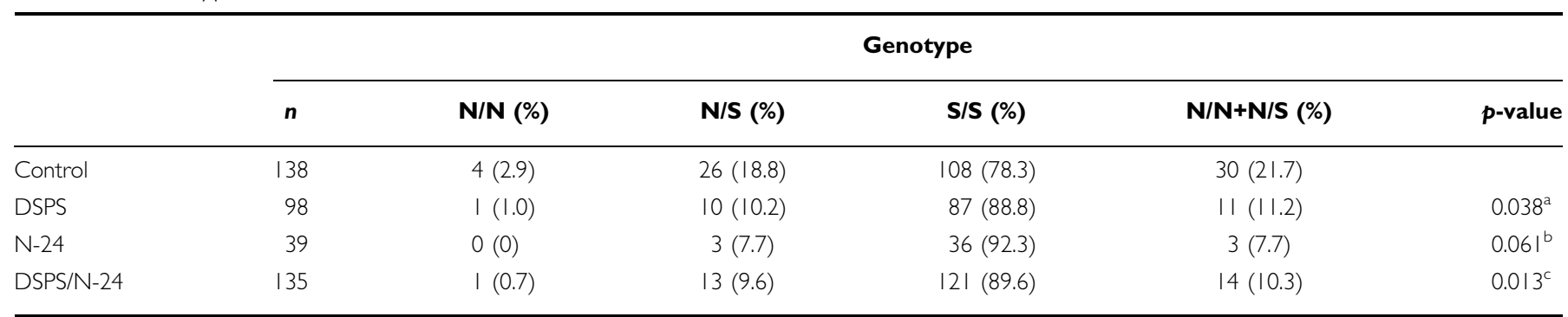

The frequency of the N408-allele carrier is shown as (N/N+N/S). Odds ratio (OR) and 95\% confidence interval (Cl) are for (N/N+N/S) vs S/S.

${ }^{\mathrm{a}} \mathrm{OR}=0.46,95 \% \mathrm{Cl}: 0.22-0.96$.

${ }^{\mathrm{b}} \mathrm{OR}=0.3,95 \% \mathrm{Cl}: 0.086-1.04$

${ }^{\mathrm{C}} \mathrm{OR}=0.42,95 \% \mathrm{Cl}: 0.21-0.83$.

Two of the DSPS subjects, who had siblings with N-24, were excluded from the combined DSPS/N-24 group to avoid an increase in the Type I error rate. Neither of the sibling pairs carried the S408N variation.

$\mathrm{CKI} \varepsilon$ gene, which was located $40 \mathrm{bp}$ downstream of $\mathrm{S} 408 \mathrm{~N}$ polymorphic site (Table 2). One of the DSPS patients and two of the $\mathrm{N}-24$ patients were heterozygous for the $1263 \mathrm{~A}>\mathrm{G}$ variation, while it was not detected in the control individuals. However, the frequency of the $1263 \mathrm{~A}>\mathrm{G}$ variation was too low to establish whether the variation affects the development of DSPS and N-24.

The N408 allele was significantly less frequent in DSPS $(p=0.028)$ and in $\mathrm{N}-24(p=0.035)$ than in control subjects (Table 3). The frequency of the N408-allele carrier was also significantly lower in DSPS subjects $(p=0.038)$ compared to controls, while the difference in carrier frequency between $\mathrm{N}-24$ subjects and controls showed a similar tendency but did not come to statistical significance $(p=0.061)$ (Table 4$)$. $\mathrm{N}-24$ patients often suffer from DSPS during the course of the illness (Kamgar-Parsi et al, 1983; Oren and Wehr, 1992; McArthur et al, 1996), and reportedly share some of the physiological characteristics of DSPS, such as prolonged interval between natural wake time and the core body temperature trough (Uchiyama et al, 2000) or melatonin midpoint (Shibui et al, 1999; Uchiyama et al, 2002). These observations led to an a priori prediction that DSPS and N24 are essentially the same disorder expressed with different degrees of severity (Weitzman et al, 1981; Campbell et al, 1999; Regestein and Monk, 1995). Indeed, when DSPS and N-24 subjects were combined, highly significant inverse associations were found between the N408 variant and DSPS/N-24 in both allele frequency $(p=0.0067$, odds ratio $(\mathrm{OR})=0.42,95 \%$ confidence interval $(\mathrm{CI}): 0.22-0.79)$ and carrier frequency $(p=0.013, \mathrm{OR}=0.42,95 \% \mathrm{CI}: 0.21-0.83)$, suggesting that the $\mathrm{N} 408$ allele protects against the development of DSPS/N-24. Our sample size had a $78 \%$ power to detect this effect of the $S 408 \mathrm{~N}$ allele at a significance level of $p=0.05$.

We next considered whether the $S 408 \mathrm{~N}$ variation induces a functional alteration in $\mathrm{CKI} \varepsilon$, as expected from the location of the substitution. To determine whether the N408 variation in $\mathrm{CKI} \varepsilon$ affects kinase activity in situ, phosphorylation of PER1 was assayed in transfected COS-7 cells by pulse-chase analysis. COS-7 cells were co-transfected with expression plasmids encoding mPer1 and either wild-type $\mathrm{rCKI} \varepsilon$ or $\mathrm{rCKI} \varepsilon$ with the $\mathrm{S} 408 \mathrm{~N}$ substitution. The transfected cells were pulse-labeled with $\left[{ }^{35} \mathrm{~S}\right]$ methionine for $1 \mathrm{~h}$ and chased for $0-6 \mathrm{~h}$. After the chase period, cells were lysed and mPER1 protein expressed in COS-7 cells was immunopre- cipitated using anti-mPER1 antibody. The immunoprecipitates were electrophoresed, and $\left[{ }^{35} \mathrm{~S}\right]$-labeled mPER 1 was detected. $\mathrm{rCKI} \varepsilon$ with the $\mathrm{S} 408 \mathrm{~N}$ substitution induced a more pronounced mobility shift and reduced mPER1 protein level at $6 \mathrm{~h}$ post-pulse, which was indistinguishable from the effects induced by wild-type $\mathrm{rCKI} \varepsilon$. These results indicate that, in situ, wild-type $\mathrm{rCKI} \varepsilon$ and $\mathrm{rCKI} \varepsilon$ with the S408N substitution induce similar levels of phosphorylation and subsequent instability of the mPER1 protein (data not shown).

Previous reports suggested that subsets of autophosphorylation sites in CKIE are dephosphorylated in HEK293 and NIH3T3 cells by endogenous phosphatases, thus activating CKI $\varepsilon$ activity (Gietzen and Virshup, 1999; Rivers et al, 1998). Therefore, it is possible that rCKI 8 s transfected into COS-7 cells are dephosphorylated, consequently masking the effect of the $\mathrm{S} 408 \mathrm{~N}$ substitution on kinase activity.

To test this hypothesis, we performed in vitro kinase assays of GST-CKI $\varepsilon$ with or without the S408N substitution, using $\alpha$-casein as a substrate. Recombinant GST-CKI $\varepsilon$ proteins were expressed in $E$. coli, purified with glutathione sepharose $4 \mathrm{~B}$, and immunoprecipitated with the C-terminus-specific antibody for CKI $\varepsilon$ to remove partially degraded protein. The kinetic analysis was performed using varying substrate concentrations $(0-100 \mu \mathrm{M})$. As expected, GSTCKI $8-S 408 \mathrm{~N}$ exhibited higher kinase activity than GST$\mathrm{CKI} \varepsilon-\mathrm{WT}$ (Figure 1a). The data were represented as a double-reciprocal plot (Figure 1b). GST-CKI $\varepsilon-S 408 \mathrm{~N}$ showed significantly increased $V_{\max }(181 \%$ of GST-CKI $\varepsilon-$ WT) and a slightly decreased apparent $K_{\mathrm{m}}$ (78\% of GST$\mathrm{CKI} \varepsilon-\mathrm{WT}$ ) against casein. To investigate whether the $\mathrm{S} 408 \mathrm{~N}$ substitution in $\mathrm{CKI} \varepsilon$ causes higher enzyme activity on endogenous clock components, in vitro kinase assays using GST-PERs as substrates were also performed. To distinguish the phosphorylated GST-PERs from autophosphorylated CKI $s$, GST tags were removed from recombinant CKI $\varepsilon s$. As shown in Figure 2, CKI $\varepsilon-S 408 \mathrm{~N}$ incorporated more $\left[{ }^{32} \mathrm{P}\right]$ into PER1, PER2, and PER3 fragments, respectively, than $\mathrm{CKI} \varepsilon-\mathrm{WT}$ did.

\section{DISCUSSION}

$\mathrm{CKI} \varepsilon$ is one of the seven isoforms of CKI, designated $\alpha, \beta$, $\gamma 1-3, \delta$, and $\varepsilon$ (Eide and Virshup, 2001). Activity of CKI $\varepsilon$ 
a 으는요은 autophosphorylated
GST - CKI $\varepsilon$
$\alpha$-casein [

GST - CKI $\varepsilon$ - WT

GST - CKI $\varepsilon-\mathrm{S} 408 \mathrm{~N}$

b

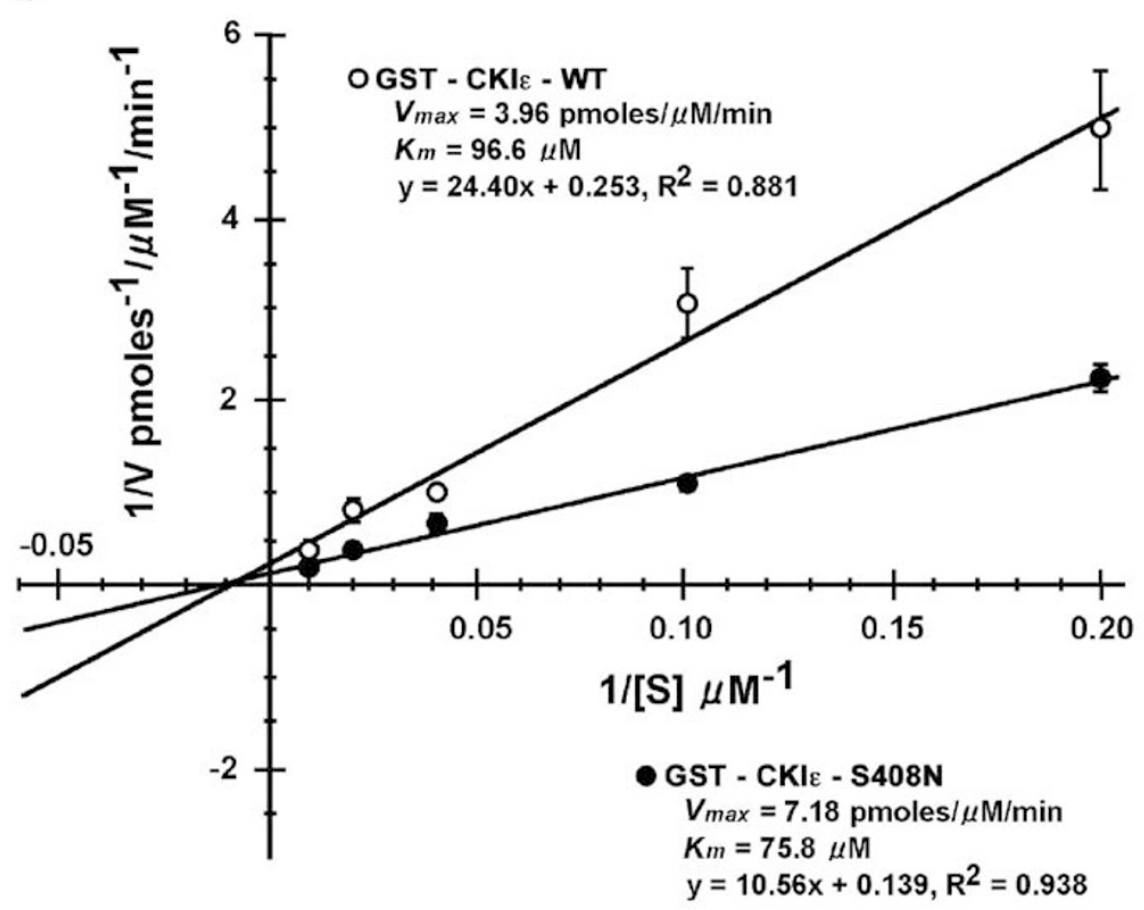

Figure I Kinetic analysis of recombinant GST-CKI\& for $\alpha$-casein. (a) Assays were performed with various concentrations of $\alpha$-casein in the presence of

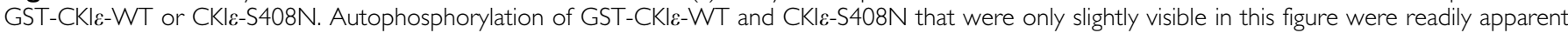
when increased amounts of recombinant enzymes were used (data not shown). (b) Double-reciprocal plot of the data derived from the kinase assay performed with various concentrations of $\alpha$-casein. Open and closed circles indicate the results for GST-CKIE-WT and CKIE-S408N, respectively. Calculated

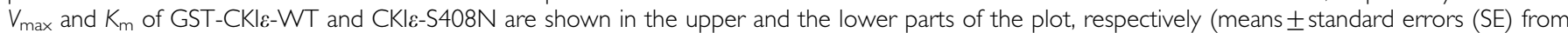
three independent experiments).

(and the closely related $\mathrm{CKI} \delta$ ) is regulated in part by autophosphorylation of the C-terminal extension (Eide and Virshup, 2001; Graves and Roach, 1995; Cegielska et al, 1998). In vitro, CKI $\varepsilon$ is highly autophosphorylated, which inhibits enzyme activity (Gietzen and Virshup, 1999; Rivers et al, 1998). Both dephosphorylation by phosphatase treatment and removal of the C-terminal domain reactivate the kinase (Graves and Roach, 1995; Cegielska et al, 1998). In a site-directed mutagenesis study, eight amino acids in the C-terminal domain were identified as probable autophosphorylation sites, including serine-408 (Gietzen and Virshup, 1999). Therefore, the amino-acid change from serine-408 to asparagine ( $\mathrm{S} 408 \mathrm{~N})$ in $\mathrm{CKI} \varepsilon$, which was found in this study, is likely to eliminate one of the autophosphorylation sites, and is expected to reactivate part, but not all, of the kinase activity. Indeed, in our in vitro kinase assay with $\alpha$-casein, recombinant GST-CKI $\varepsilon$ with the S408N substitution purified from $E$. coli exhibited a moderate (1.8-fold) elevation of specific activity compared to that of wild-type GST-CKI $\varepsilon$, while a previous study showed that a mutant $\mathrm{CKI} \varepsilon$, in which all of the putative autophosphorylation sites are disrupted, was eight-fold more active than wild-type CKI $\varepsilon$ (Gietzen and Virshup, 1999). The moderate elevation of $\mathrm{CKI} \varepsilon$ activity by $\mathrm{S} 408 \mathrm{~N}$ substitution was 


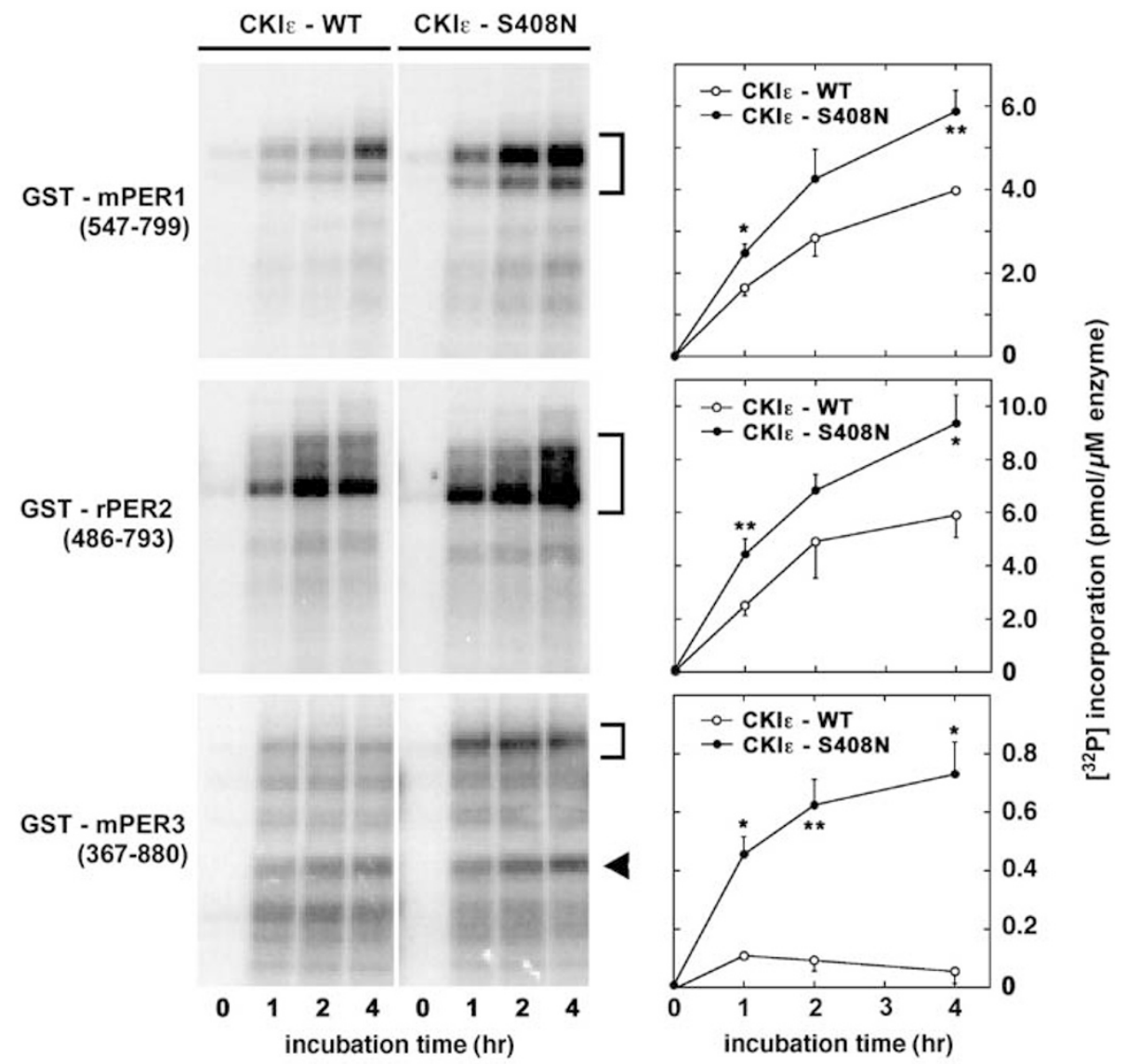

Figure 2 In vitro kinase assay of recombinant CKI $\varepsilon$ using GST-fused PER fragments as substrates. GST-mPERI (amino acids 547-799) (top panels), GSTrPER2 (486-793) (middle panels), or GST-mPER3 (367-880) (bottom panels) fragment was incubated with recombinant CKle-WT or CKle-S408N for the indicated duration and analyzed by $7.5 \%$ polyacrylamide gels as described in Materials and methods. Representative autoradiograms are shown. Angle brackets indicate the phosphorylated GST-PER fragments. Arrowhead indicates autophosphorylated CKIE (left panels). Incorporated [ $\left.{ }^{32} \mathrm{P}\right]$ was quantified and normalized to the total amount of kinase used (means \pm SE from three to five independent experiments). Statistically significant differences in [ ${ }^{32} \mathrm{P}$ ] incorporation induced by $\mathrm{CKI} \varepsilon-\mathrm{WT}$ and $\mathrm{CKI} \varepsilon-\mathrm{S} 408 \mathrm{~N}$ are shown by asterisks $(* p<0.05$, $* * 0<0.0 \mathrm{I}$ ) (right panels).

identically observed in the in vitro kinase assay with each of the three subtypes of PER proteins, which are endogenous substrates for CKI $\varepsilon$. It is intriguing that $\mathrm{CKI} \varepsilon-\mathrm{S} 408 \mathrm{~N}$ induced more phosphorylation of PER3 than CKIE-WT did, because we have previously reported that a $\operatorname{Per} 3$ gene haplotype, which presumably alters PER3 protein phosphorylation, is significantly associated with DSPS (Ebisawa et al, 2001). However, it should be noted that we observed much less phosphorylation of PER3 compared with that of PER1 or PER2, which is consistent with the previous reports showing CKI $\varepsilon$-induced phosphorylation of PER3 (Takano et al, 2000; Akashi et al, 2002) and unstable interaction of PER3 with CKI $\varepsilon$ in the absence of PER1 (Akashi et al, 2002; Lee $e t$ al, 2004). We could not find any elevation of enzyme activity in pulse-chase analysis in situ, presumably because of dephosphorylation by endogenous phosphatases as described in 'Results', or because the analysis was insufficiently sensitive to detect a moderate difference of activity.

The tau mutation in hamster CKIE decreases kinase activity by as much as eight-fold (Lowrey et al, 2000), whereas the $S 408 \mathrm{~N}$ variant in hCKIE results in only 1.8 -fold change (an increase) in the activity. This difference might explain the reason why the $\mathrm{N} 408$ allele of hCKIE induces a significant but modest effect $(\sim 2$-fold reduction in the risk to develop DSPS/N-24), compared with the tau mutation in hamster CKIE, which causes a semidominant short-period phenotype (Ralph and Menaker, 1988).

Studies in flies and mammals suggest that CKI $\varepsilon$ binds to and phosphorylates PER proteins, leading to instability and intracellular relocalization of the PERs (Takano et al, 2000; Vielhaber et al, 2000; Keesler et al, 2000; Akashi et al, 2002). Mutant CKIE in the Syrian Golden hamster is deficient in PER phosphorylation (Lowrey et al, 2000). Per2 S662G mutation in a reported familial ASPS cause hypophosphorylation by CKI $\varepsilon$ (Toh et al, 2001). In both cases, the PER protein(s) seems to undergo delayed degradation and accelerated accumulation, leading to hastened nuclear entry and shortened circadian period. In contrast, in flies with $d b t^{L}$ or $d b t^{a r}$ (long-period alleles of $d b t$, the Drosophila homolog of $C K I \varepsilon)$, it is likely that delayed phosphorylation and increased nuclear stability of PER protein slow the rate of PER elimination from the nucleus and lengthen circadian rhythm (Price et al, 1998; Rothenfluh et al, 2000). Therefore, hypophosphorylation of PER protein appears to cause different phenotypes depending on the subcellular localization of the stabilized PERs. hCKI $\varepsilon$ with an S408N substitution appears more active than wild type only when 
the protein is autophosphorylated. A recent study suggests that the autophosphorylation level of $\mathrm{CKI} \varepsilon$, in neuroblastoma N2a cells, is dynamically regulated through transient dephosphorylation and subsequent phosphorylation, thus regulating the kinase activity (Liu et al, 2002). Additionally, in clock-relevant cells, CKI $\varepsilon$ intracellular localization is under circadian control (Lee et al, 2001); therefore, it is possible that a dynamic autophosphorylation/dephosphorylation cycle could differentially regulate $\mathrm{CKI} \varepsilon$ activity at different subcellular locations in pacemaker cells. The S408N variation of hCKIE might alter circadian rhythmicity through increased phosphorylation and decreased stability of PER protein; the expected phenotypic consequences, however, would differ depending on the levels of $\mathrm{CKI} \varepsilon$ autophosphorylation in each subcellular location. It will be of interest to investigate the autophosphorylation status of $\mathrm{CKI} \varepsilon-\mathrm{S} 408 \mathrm{~N}$ and to clarify its functional role in circadian clock machinery.

Although a significant inverse association was observed between the N408 variant and DSPS/N-24, 10.3\% of the patients carried the $\mathrm{N} 408$ allele, indicating that DSPS/N-24 is genetically heterogeneous and multiple genes affect susceptibility to the development of DSPS/N-24.

The $1263 \mathrm{~A}>\mathrm{G}$ variation in the $3^{\prime}$-untranslated region of hCKIE was detected only in three of the rhythm disorder subjects, but not in controls. A larger sample size will be necessary to ascertain its relevance to DSPS/N-24.

Owing to the potential role of $\mathrm{CKI} \varepsilon$ in the circadian rhythm, all of the coding exons in hCKIE gene were screened for variations in circadian rhythm sleep disorder patients and controls. We found a missense variation $\mathrm{S} 408 \mathrm{~N}$, for the first time, which eliminates one of the putative autophosphorylation sites in hCKI $\varepsilon$ and confers 1.8 -fold higher enzyme activity in vitro. There was a significant difference in the frequency of N408 allele between controls and DSPS or $\mathrm{N}-24$, respectively, with an excess of $\mathrm{N} 408$ allele in controls. When considering the whole sample of circadian rhythm sleep disorders (DSPS/N-24), we found a highly significant inverse association between $\mathrm{N} 408$ allele and DSPS $/ \mathrm{N}-24 \quad(p=0.0067, \quad \mathrm{OR}=0.42,95 \%$ CI: $0.22-0.79)$. These results indicate that the N408 allele of the hCKIs gene is a marker for decreased risk of DSPS/N-24. S408N variation would also be useful to investigate other disorders related to disturbed circadian rhythm or interindividual differences of circadian rhythmicity in apparently normal subjects (Johansson et al, 2003). Our results will yield a new insight into the mechanism of DSPS/N-24 and raise a question in the role of $\mathrm{CKI} \varepsilon$ autophosphorylation on mammalian clock functioning.

\section{ACKNOWLEDGEMENTS}

We wish to express appreciation for the cooperation of all the participants. We thank Dr Mariko Nagao, Dr Keiko Kim, and Dr Yoshihisa Kudo for recruiting patients. Technical contributions by Mr Eiichi Yamada, Ms Kyoko Ohnishi, and Mr Masakazu Kinoshita are gratefully acknowledged. This work was supported financially by the Ministry of Health and Welfare, and the Ministry of Education, Science, Sports, and Culture (10557089, 11233206, 12470198), and Saitama Medical School.

\section{REFERENCES}

Akashi M, Tsuchiya Y, Yoshino T, Nishida E (2002). Control of intracellular dynamics of mammalian period proteins by casein kinase $\mathrm{I} \varepsilon(\mathrm{CKI} \varepsilon)$ and $\mathrm{CKI} \delta$ in cultured cells. Mol Cell Biol 22: 1693-1703.

Ancoli-Israel S, Schnierow B, Kelsoe J, Fink R (2001). A pedigree of one family with delayed sleep phase syndrome. Chronobiol Int 18: 831-840.

Ando K, Kripke DF, Ancoli-Israel S (1995). Estimated prevalence of delayed and advanced sleep phase syndromes. Sleep Res 24: 509.

Burset M, Seledtsov IA, Solovyev VV (2000). Analysis of canonical and non-canonical splice sites in mammalian genomes. Nucleic Acids Res 28: 4364-4375.

Camacho F, Cilio M, Guo Y, Virshup DM, Patel K, Khorkova O et al (2001). Human casein kinase $\mathrm{I} \delta$ phosphorylation of human circadian clock proteins period 1 and 2. FEBS Lett 489: 159-165.

Campbell SS, Murphy PJ, van den Heuvel CJ, Roberts ML, Stauble TN (1999). Etiology and treatment of intrinsic circadian rhythm sleep disorders. Sleep Med Rev 3: 179-200.

Cegielska A, Gietzen KF, Rivers A, Virshup DM (1998). Autoinhibition of casein kinase $\mathrm{I} \varepsilon(\mathrm{CKI} \varepsilon)$ is relieved by protein phosphatases and limited proteolysis. J Biol Chem 273: 1357-1364.

den Dunnen JT, Antonarakis E (2001). Nomenclature for the description of human sequence variations. Hum Genet 109: 121-124.

Ebisawa T, Uchiyama M, Kajimura N, Mishima K, Kamei Y, Katoh $M$ et al (2001). Association of structural polymorphisms in the human period3 gene with delayed sleep phase syndrome. EMBO Rep 2: 342-346.

Eide EJ, Virshup DM (2001). Casein kinase I: another cog in the circadian clockworks. Chronobiol Int 18: 389-398.

Gietzen KF, Virshup DM (1999). Identification of inhibitory autophosphorylation sites in casein kinase I $\varepsilon$. J Biol Chem 274: 32063-32070.

Graves PR, Roach PJ (1995). Role of COOH-terminal phosphorylation in the regulation of casein kinase I $\delta$. J Biol Chem 270: 21689-21694.

Harmer SL, Panda S, Kay SA (2001). Molecular bases of circadian rhythms. Annu Rev Cell Dev Biol 17: 215-253.

Iwase $T$, Kajimura N, Uchiyama $M$, Ebisawa $T$, Yoshimura $K$, Kamei Y et al (2002). Mutation screening of the human Clock gene in circadian rhythm sleep disorders. Psychiatry Res 109: 121-128.

Johansson C, Willeit M, Smedh C, Ekholm J, Paunio T, Kieseppa T et al (2003). Circadian clock-related polymorphisms in seasonal affective disorder and their relevance to diurnal preference. Neuropsychopharmacology 28: 734-739.

Jones CR, Campbell SS, Zone SE, Cooper F, DeSano A, Murphy PJ et al (1999). Familial advanced sleep-phase syndrome: a shortperiod circadian rhythm variant in humans. Nat Med 5: 1062-1065.

Kamgar-Parsi B, Wehr TA, Gillin JC (1983). Successful treatment of human non-24-h sleep-wake syndrome. Sleep 6: 257-264.

Keesler GA, Camacho F, Guo Y, Virshup D, Mondadori C, Yao Z (2000). Phosphorylation and destabilization of human period1 clock protein by human casein kinase I\&. Neuroreport 11: 951-955.

Lee C, Etchegaray J-P, Cagampang FRA, Loudon ASI, Reppert SM (2001). Posttranslational mechanisms regulate the mammalian circadian clock. Cell 107: 855-867.

Lee C, Weaver DR, Reppert SM (2004). Direct association between mouse PERIOD and CKI $\varepsilon$ is critical for a functioning circadian clock. Mol Cell Biol 24: 584-594. 
Liu F, Virshup DM, Nairn AC, Greengard P (2002). Mechanism of regulation of casein kinase I activity by group I metabotropic glutamate receptors. J Biol Chem 277: 45393-45399.

Lowrey PL, Shimomura K, Antoch MP, Yamazaki S, Zemenides PD, Ralph MR et al (2000). Positional syntenic cloning and functional characterization of the mammalian circadian mutation tau. Science 288: 483-491.

McArthur AJ, Lewy AJ, Sack RL (1996). Non-24-h sleep-wake syndrome in a sighted man: circadian rhythm studies and efficacy of melatonin treatment. Sleep 19: 544-553.

Oren DA, Wehr TA (1992). Hypernyctohemeral syndrome after chronotherapy for delayed sleep phase syndrome. New Engl J Med 327: 1762.

Perneger TV (1998). What's wrong with Bonferroni adjustments. Br Med J 316: 1236-1238.

Price JL, Blau J, Rothenfluh A, Abodeely M, Kloss B, Young MW (1998). Double-time is a novel Drosophila gene that regulates PERIOD protein accumulation. Cell 94: 83-95.

Ralph MR, Menaker M (1988). A mutation of the circadian system in golden hamsters. Science 241: 1225-1227.

Regestein QR, Monk TH (1995). Delayed sleep phase syndrome: a review of its clinical aspects. Am J Psychiatry 152: 602-608.

Reid KJ, Chang A-M, Dubocovich ML, Turek FW, Takahashi JS, Zee PC (2001). Familial advanced sleep phase syndrome. Arch Neurol 58: 1089-1094.

Reppert SM, Weaver DR (2002). Coordination of circadian timing in mammals. Nature 418: 935-941.

Rivers A, Gietzen KF, Vielhaber E, Virshup DM (1998). Regulation of casein kinase $\mathrm{I} \varepsilon$ and casein kinase $\mathrm{I} \delta$ by an in vivo futile phosphorylation cycle. J Biol Chem 273: 15980-15984.

Rothenfluh A, Abodeely M, Young MW (2000). Short-period mutations of per affects a double-time-dependent step in the Drosophila circadian clock. Curr Biol 10: 1399-1402.
Schrader H, Bovim G, Sand T (1993). The prevalence of delayed and advanced sleep phase syndromes. $J$ Sleep Res 2: 51-55.

Shibui K, Uchiyama M, Okawa M (1999). Melatonin rhythms in delayed sleep phase syndrome. J Biol Rhythms 14: 72-76.

Takano A, Shimizu K, Kani S, Buijs RM, Odaka M, Nagai K (2000). Cloning and characterization of rat casein kinase $1 \varepsilon$. FEBS Lett 477: $106-112$.

Toh KL, Jones CR, He Y, Eide EJ, Hinz WA, Virshup DM et al (2001). An hPer2 phosphorylation site mutation in familial advanced sleep phase syndrome. Science 291: 1040-1043.

Uchiyama M, Okawa M, Shibui K, Kim K, Tagaya H, Kudo Y et al (2000). Altered phase relation between sleep timing and core body temperature rhythm in delayed sleep phase syndrome and non-24-h sleep-wake syndrome in humans. Neurosci Lett 294: 101-104.

Uchiyama M, Shibui K, Hayakawa T, Kamei Y, Ebisawa T, Tagaya $\mathrm{H}$ et al (2002). Larger phase angle between sleep propensity and melatonin rhythms in sighted humans with non-24-h sleep-wake syndrome. Sleep 25: 83-88.

Vielhaber E, Eide E, Rivers A, Gao Z-H, Virshup DM (2000). Nuclear entry of the circadian regulator mPER1 is controlled by mammalian casein kinase IE. Mol Cell Biol 20: 4888-4899.

Weitzman ED, Czeisler CA, Coleman RM, Spielman AJ, Zimmerman JC, Dement W (1981). Delayed sleep phase syndrome. A chronobiological disorder with sleep-onset insomnia. Arch Gen Psychiatry 38: 737-746.

Wijnen H, Boothroyd C, Young MW, Claridge-Chang A (2002). Molecular genetics of timing in intrinsic circadian rhythm sleep disorders. Ann Med 34: 386-393.

Yazaki M, Shirakawa S, Okawa M, Takahashi K (1999). Demography of sleep disturbances associated with circadian rhythm disorders in Japan. Psychiat Clin Neurosci 53: 267-268. 